\title{
Impact of Clean Delivery-kit use on Newborn Umbilical Cord and Maternal Puerperal Infections in Egypt
}

\author{
Gary L. Darmstadt', Mohamed Hassan ',2, Zohra P. Balsara', Peter J.Winch', \\ Reginald Gipson², and Mathuram Santosham' \\ 'International Center for Advancing Neonatal Health, Department of International Health, Bloomberg School of Public Health, \\ Johns Hopkins University, 615 North Wolfe Street, Baltimore, MD, USA and ${ }^{2}$ Healthy Mother/Healthy Child Results Package, \\ John Snow Inc., Cairo, Egypt
}

ABSTRACT

This cross-sectional cohort study explored the impact of the use of clean delivery-kit (CDK) on morbidity due to newborn umbilical cord and maternal puerperal infections. Kits were distributed from primary-care facilities, and birth attendants received training on kit-use. A nurse visited 334 women during the first week postpartum to administer a structured questionnaire and conduct a physical examination of the neonate and the mother. Results of bivariate analysis showed that neonates of mothers who used a CDK were less likely to develop cord infection ( $\mathrm{p}=0.025$ ), and mothers who used a CDK were less likely to develop puerperal sepsis $(\mathrm{p}=0.024)$. Results of multiple logistic regression analysis showed an independent association between decreased cord infection and kit-use [odds ratio $(\mathrm{OR})=0.42,95 \%$ confidence interval (CI) 0.18-0.97, $\mathrm{p}=0.041)]$. Mothers who used a $\mathrm{CDK}$ also had considerably lower rates of puerperal infection $(\mathrm{OR}=0.11,95 \%$ CI 0.01-1.06), although the statistical strength of the association was of borderline significance $(\mathrm{p}=0.057)$. The use of CDK was associated with reductions in umbilical cord and puerperal infections.

Key words: Cohort studies; Cross-sectional studies; Delivery-kit; Evaluation studies; Impact studies; Morbidity; Sepsis; Umbilical cord infections; Egypt

\section{INTRODUCTION}

Each year, an estimated four million neonatal deaths occur globally (1). Infections account for $36 \%$ of these deaths (1). Serious systemic infections, including sepsis, meningitis, and pneumonia, account for $26 \%$ of neonatal deaths while neonatal tetanus and diarrhoea account for $7 \%$ and $3 \%$ respectively (1). Although precise data on the relationship between cord infections and sepsis are lacking, a substantial proportion of neonatal sepsis and meningitis may stem from infections of the umbilical cord (2-5), and cord infections are associated with increased risk for mortality (6). Furthermore, puerperal sepsis causes an estimated $15 \%$ of all maternal deaths, or

Correspondence and reprint requests should be addressed (present address) to:

Dr. Gary L. Darmstadt

Integrated Health Solutions Development

Global Health Program

Bill \& Melinda Gates Foundation

PO Box 23350

Seattle, WA 98102

USA

Email: gary.darmstadt@gatesfoundation.org approximately 75,000 deaths per year worldwide, most of which occur in developing countries (7-9).

In most developing countries, almost half of all births take place in the home, and an untrained birth attendant is present at one in every four births $(9,10)$. A major factor contributing to neonatal and maternal infections is delivery in the home under unhygienic conditions, increasing the likelihood of pathogenic microorganisms entering the cordstump of the neonate or birth-canal of the mother $(8,11)$. Tetanus toxoid immunization for pregnant women is an effective means of reducing neonatal and maternal deaths due to tetanus but a large number of babies and mothers continue to die due to bacterial infections transmitted during unclean deliveries (12).

The importance of infection as a cause of neonatal death varied whether defined based on Wigglesworth classification (7\%), World Health Organization (WHO) estimates (13\%), or a panel of two Egyptian neonatologists (20\%) (13). A study to explore neonatal care-practices conducted in three Governorates of Egypt found umbilical stump-ooz- 
ing, redness, and tenderness during the first week of life in $4 \%, 6 \%$, and $7 \%$ of newborns respectively (14). In Nepal (15) and Tanzania (16), 1-15\% and $1-12 \%$ of newborns respectively were found to have omphalitis, depending on the combination of clinical signs used to define the condition.

Infection ranks third among the direct causes of maternal mortality in Egypt, accounting for 8\% of all deaths (17). Substandard home-delivery practices of daya [traditional birth attendant (TBA)] were identified as significant risk factors associated with mortality due to sepsis $(17,18)$.

Research by the WHO suggests that pre-assembled clean delivery-kits (CDKs), with instructions for use, can be a vital component in improving hygiene at delivery, particularly for deliveries conducted by unskilled care providers (19). The CDK promotes and supports the use of clean delivery practices, specifically the 'cleans' defined by the WHO, i.e. clean hands, perineum, delivery surface, cord-cutting surface, cord-cutting, and tying instruments (20).

Studies have been conducted in several countries on the use and impact of CDKs (20-25). In Tanzania, Mosha et al. concluded that the use of a CDK, when coupled with an educational intervention about the 'six cleans', was strongly associated with lower incidences of umbilical cord infection and puerperal sepsis (25). In Nepal, Tsu found that infections of the umbilical cord were reduced by more than half among users of the clean blade and clean-cutting surface provided in CDKs (23).

In recent years, significant resources have been invested in promoting safe and hygienic delivery care by health professionals in facilities equipped to provide basic essential obstetric care. While this approach is sound, there is concern that it may be inadequate, particularly in settings, such as rural areas of Middle and Upper Egypt, where almost 50\% of all births still take place in the home and almost $40 \%$ of which are typically attended to by a daya or a family member (26). In 1998, in an effort to improve delivery care in all settings, the Egyptian Ministry of Health and Population (MoHP) introduced CDKs through existing primary healthcare facilities in certain Governorates across the country. However, there have been no evaluations of the independent effect of the programmatic distribution of CDKs on maternal and neonatal health outcomes. This study evaluated the impact of the use of CDKs, in Beni Suef Governorate, on morbidity due to puerperal and umbilical infections.

\section{MATERIALS AND METHODS}

\section{Study site}

The study was conducted in three areas of Ihnasia district in Beni Suef Governorate (Middle Egypt)— Ihnasia city and two rural areas, namely Awana and Nena. The sites were selected based on the availability of raedat (trained community workers) and trained dayas. The district director was a qualified female obstetrician who helped facilitate study logistics, including postnatal home-visits. Verbal consent was obtained from all the study women. The study was approved by the Healthy Mother/ Healthy Child Results Package project of the MoHP in collaboration with John Snow Inc. (JSI).

\section{Promotion, distribution, and contents of clean delivery-kit}

CDKs were made available in the third week of March 2001 at primary healthcare facilities identified by the MoHP within the study area. JSI provided CDKs to the MoHP for distribution. Facilities were provided with CDKs proportional to the expected number of births for the catchment area of that facility for five months. Each facility nurse was responsible for providing CDKs to the appropriate groups of people, i.e. pregnant women who came for antenatal care (ANC), dayas, and skilled birth attendants (physicians, nurses, and midwives) performing deliveries in the study catchment areas.

Training for raedat, dayas, and facility nurses was conducted by Egypt project staff of JSI, along with trainers locally hired for this project. Raedat were asked to maintain a record of all pregnancies and deliveries within their assigned areas. A raeda visited each pregnant woman in the home. The purpose of this visit was to motivate the women to attend ANC and to obtain a CDK from the local health facility. Women were instructed on the importance and use of the CDK and sanitary disposal of each item. Dayas attending deliveries within the study area were also trained on the importance of ANC and on handling, use, and appropriate disposal of each item in the CDK. Each daya was given five kits to be used for women who had not obtained one during ANC. All skilled birth attendants who conducted deliveries in the home or in public or private facilities were encouraged to use the CDK and given kits on demand. They received training on the importance of ANC and the CDK and on the use, handling, and disposal of items. JSI and the MoHP locally designed the kit. The kit contained an opaque white plastic sheet, a roll of gauze, a 
sterilized and sealed umbilical cord clamp, a sterile single-use disposable scalpel, two sterile and sealed gauze sponges, one pair of sterile latex surgical gloves, a sterile single-use bulb-syringe, sealed Dixon thread, two sealed swabs saturated with 70\% isopropyl alcohol, a sealed container of $10 \%$ Povidone iodine, a plastic single-use apron, and a pictorial instruction-sheet for kit-use and danger signs that require immediate referral.

\section{Postnatal visit}

This cross-sectional cohort study included all mothers who recently delivered in the study area from mid-June through mid-July 2001. A nurse from the closest primary healthcare centre was informed of each delivery by the raedat. The nurse visited all the women who recently delivered once during the first week postpartum, administered a structured questionnaire, and conducted a physical examination of the neonate and the mother. CDK-use was defined as the mother's response of having used a kit during her last delivery. Information on the use of specific items was not collected. The umbilical stump of the newborn was examined to detect redness, oozing, or bleeding. Rectal temperature of the newborn was measured twice, using a mercury thermometer. The mother was examined for abdominal and perineal pain, redness, and discharge. Mother's temperature was measured orally twice, using a mercury thermometer. Data were collected on factors which could have a potential association with infection, including CDK-use, place and type of delivery, and birth attendant. Neonates and women found to be ill during home-visits were referred to and assisted in obtaining treatment from government facilities.

Periodic random field-checks, including re-interview of a sample of women by a qualified female obstetrician, were conducted to ensure the quality of data. Matching of data revealed a discrepancy rate of $<5 \%$. Where there were discrepancies, supervisory field-visits were conducted, including re-interview of the woman and on-the-spot retraining of nurses and raedat. All data-collection instruments were developed and administered in colloquial Arabic.

\section{Analysis of data}

Analysis of data focused on measuring the impact of CDK-use on risk of umbilical cord infection and puerperal sepsis. Umbilical cord infection was defined as having both of the following symptoms: (a) cord-stump redness and (b) stump oozing or bleeding on examination by the nurse during a postnatal visit (4). Puerperal sepsis was defined as the presence of at least two of the following three symptoms: (a) fever, i.e. oral temperature $>38.5^{\circ} \mathrm{C}$, (b) perineum pain, and (c) abnormal vaginal discharge (abnormal colour and foul odour) on examination by the nurse during a postpartum visit (12). Bivariate tests of association to investigate factors other than CDK-use that were associated with cord and puerperal infections were done using the Fisher's Exact chi-square test, with level of significance defined as $\mathrm{p}<0.05$. To examine the independent effect of CDK-use in reducing cord and puerperal infections, potential confounding factors, i.e. 'area' (urban versus rural), 'place of delivery' (facility versus home), and 'type of delivery' (forceps, ventose, and caesarean section versus normal), were adjusted for in a multiple logistic regression model. All data analyses were done using the Stata ${ }^{\circledR}$ software (version 9.0) (StataCorp LP, College Station, Texas).

\section{RESULTS}

\section{Study population}

In total, 334 women known to deliver in the study area during a one-month period were identified and enrolled. Approximately 22\%, 44\%, and 34\% of the women were from Nena, Awana, and Ihnasia city respectively. The mean age of the respondents was 26 years [standard deviation (SD) 5.13], ranging from 16 to 42 years. The mean age of the neonates was three days (SD 2.74); 90\% were aged $\leq 5$ days at the time of the visit. About $57 \%$ of the neonates $(\mathrm{n}=334)$ were male $(\mathrm{n}=190)$, and $43 \%$ were female $(n=144)$. Approximately $84 \%$ of the mothers delivered in the home. Of all deliveries, 64\% were attended by a daya, $34 \%$ by a skilled birth attendant, and $2 \%$ by relatives and neighbours. A CDK was used in approximately $71 \%$ of the deliveries; for deliveries in the home, approximately $75 \%$ used a CDK.

\section{Cord and puerperal infections}

There were $27(8.1 \%)$ confirmed cases of cord infection and five $(1.5 \%)$ confirmed cases of puerperal sepsis (Table 1). In total, 328 women had complete information on CDK-use. Of these, 315 had complete information on 'area' (urban versus rural), 'place of delivery' (home versus facility), 'type of delivery' (ventose/forceps/caesarean section versus normal), and 'type of birth attendant' (daya/family/neighbour versus skilled). Overall, we had complete data for $94.3 \%$ of the women who recently delivered. 


\begin{tabular}{|lccc|}
\hline \multicolumn{2}{|c|}{$\begin{array}{l}\text { Table 1. Number of cases of umbilical cord and puerperal infection in relation to the use of clean } \\
\text { delivery-kit }\end{array}$} & \multicolumn{2}{c|}{ CDK-use } \\
\cline { 2 - 3 } Infection & Yes & To & \\
\hline Cord infection & 14 & 13 & $27(8.2)$ \\
Yes & 221 & 80 & $301(91.8)$ \\
No & $235(71.6)$ & $93(28.4)$ & $328(100)$ \\
Total & & & $5(1.5)$ \\
Puerperal infection & 1 & 4 & $323(98.5)$ \\
Yes & 234 & 89 & $328(100)$ \\
No & $235(71.6)$ & $93(28.4)$ & \\
Total & & \\
\hline Figures in parentheses indicate parcentages; CDK=Clean delivery-kit & \\
\hline
\end{tabular}

\section{Unadjusted bivariate analysis}

Use of CDK: In unadjusted bivariate analysis, neonates of mothers who used a CDK during delivery were significantly less likely to develop an infection of the umbilical cord $(\mathrm{p}=0.025)$ compared to neonates of mothers who did not use a CDK during delivery (Table 2). Mothers who used a CDK were significantly less likely to develop puerperal sepsis compared to mothers who did not use a CDK $(\mathrm{p}=0.024)$ (Table 2).

Area of delivery: Neonates who were born in the city were significantly less likely $(\mathrm{p}=0.010)$ to develop an infection of the cord compared to those born in rural areas of Nena and Awawna (Table 2). There was no significant difference in the proportion of women who developed puerperal infection among those who delivered in urban compared to rural areas (Table 2). There was no significant difference in CDK-use, type of delivery, or place of delivery among deliveries that took place in the urban or rural areas (data not shown).

Place of delivery: There was no significant difference in cord infection among the neonates according to place of delivery (Table 2). However, mothers delivering in a facility (private and public) were significantly more likely $(\mathrm{p}=0.033)$ to have puerperal infection compared to mothers delivering in the home (Table 2), possibly because a significantly higher number of women $(204 / 271,75 \%)$ used a CDK during deliveries in the home versus deliveries in the facility $(30 / 53,57 \%)(\mathrm{p}=0.007)$. Additionally, mothers delivering in the facility were significantly more likely $(\mathrm{p}<0.01)$ to have a delivery involving forceps, ventose, or caesarean section (16/54, $30 \%)$ compared to mothers delivering in the home $(1 / 276,0.40 \%)$.
Type of delivery: Type of delivery was not associated with newborn cord infections (Table 2). Mothers who had complicated deliveries (forceps or caesarean section) were significantly more likely $(\mathrm{p}=0.022)$ to develop puerperal infection compared to mothers who had a normal delivery (Table 2). Approximately $73 \%(n=229)$ of 313 mothers who had a normal delivery used a CDK, and $40 \%(\mathrm{n}=6)$ of 15 mothers who had a complicated delivery used a CDK.

Type of birth attendant: In bivariate analysis, type of birth attendant was not associated with cord or puerperal infection. Approximately $64 \%(\mathrm{n}=207)$, $35 \%(n=113)$, and $2 \%(n=6)$ of 326 mothers were delivered by a daya, skilled birth attendant, and relative/neighbour respectively. Almost $9 \%(n=10)$ of 113 babies delivered by a skilled birth attendant (physician, nurse, and midwife), 8\% ( $\mathrm{n}=16)$ of 207 babies delivered by a daya, and none of the babies delivered by a relative/neighbour developed cord infection. Seventeen percent (1/6), 2\% (2/113), and $1 \%(2 / 207)$ of mothers delivered by a relative/ neighbour, skilled birth attendant, and daya developed puerperal infection respectively. There was no significant difference in CDK-use between skilled birth attendants and the combined category of dayas/relatives/neighbours.

\section{Multiple logistic regression}

After adjusting for possible confounding factors, i.e. area and place of delivery, neonates of mothers who used a CDK during delivery had significantly decreased odds of developing a cord infection compared to those neonates of mothers who did not use a CDK during delivery ( $\mathrm{OR}=0.42,95 \% \mathrm{CI}$ 0.18-0.97; $\mathrm{p}=0.041$ ) (Table 3). In the case of puerperal infection, the association between CDK-use 


\begin{tabular}{|c|c|c|c|c|}
\hline \multirow{2}{*}{ Factor } & \multirow{2}{*}{ Total } & \multicolumn{2}{|c|}{ Infections } & \multirow{2}{*}{$\mathrm{p}$ value } \\
\hline & & No. & $\%$ & \\
\hline & & \multicolumn{2}{|c|}{ Cord infection } & \\
\hline \multicolumn{5}{|l|}{ CDK-use } \\
\hline No & 93 & 13 & 14.0 & \\
\hline Yes & 235 & 14 & 6.0 & 0.025 \\
\hline \multicolumn{5}{|l|}{ Area } \\
\hline Rural & 220 & 24 & 10.9 & \\
\hline Urban & 113 & 3 & 2.6 & 0.010 \\
\hline \multicolumn{5}{|l|}{ Place of delivery } \\
\hline Home & 276 & 21 & 7.6 & \\
\hline Facility & 54 & 5 & 9.3 & 0.592 \\
\hline \multicolumn{5}{|l|}{ Type of delivery } \\
\hline Normal & 317 & 26 & 8.2 & \\
\hline \multirow[t]{2}{*}{$\begin{array}{l}\text { Forceps and } \\
\text { caesarean section }\end{array}$} & 17 & 1 & 5.9 & 1.00 \\
\hline & & \multicolumn{3}{|c|}{ Puerperal infection } \\
\hline \multicolumn{5}{|l|}{ CDK-use } \\
\hline No & 93 & 4 & 4.3 & \\
\hline Yes & 235 & 1 & 0.4 & 0.024 \\
\hline \multicolumn{5}{|l|}{ Area } \\
\hline Rural & 220 & 2 & 0.9 & \\
\hline Urban & 113 & 3 & 2.6 & 0.341 \\
\hline \multicolumn{5}{|l|}{ Place of delivery } \\
\hline Home & 276 & 2 & 0.7 & \\
\hline Facility & 54 & 3 & 5.6 & 0.033 \\
\hline \multicolumn{5}{|l|}{ Type of delivery } \\
\hline Normal & 317 & 3 & 1.0 & \\
\hline $\begin{array}{l}\text { Forceps and } \\
\text { caesarean section }\end{array}$ & 17 & 2 & 11.8 & 0.022 \\
\hline
\end{tabular}

and puerperal infection was of borderline significance when adjusted for area and place of delivery (OR=0.11, 95\% CI 0.01-1.06; $\mathrm{p}=0.057$ ) (Table 3). Birth attendant was not included in the model due to multicolinearity with other factors and lack of association with puerperal or cord infection in bivariate analysis. Type of delivery was excluded from the model due to colinearity with place of delivery. Almost all (275/276) deliveries in the home were normal, except for one case where the delivery was conducted using forceps.

\section{DISCUSSION}

This study has shown that neonates whose mothers used a CDK were significantly less likely $(\mathrm{OR}=0.42$, $\mathrm{p}=0.041$ ) to develop an infection of the umbilical cord. Similarly, mothers who used a CDK also had considerably lower rates of puerperal infec- tion $(\mathrm{OR}=0.11)$, although the statistical strength of the association was of borderline significance $(\mathrm{p}=0.057)$; due to restricted sample size and rare outcome for puerperal infection, the analysis was relatively underpowered. This was a programme evaluation involving distribution of kits in all the three study areas; thus, despite our adjusted analysis, the potential for residual bias in kit-use must be acknowledged.

In low-resource settings where a high proportion of mothers give birth in the home without a trained birth attendant, or in ill-equipped facilities, resulting in unhygienic conditions, supplies to conduct a clean delivery are often not available. Results of bivariate analysis suggest that mothers delivering in a facility were more likely to develop puerperal infection. However, in multivariate analysis, after adjusting for other factors, this relationship was 


\begin{tabular}{|c|c|c|c|}
\hline \multirow[t]{2}{*}{ Factor } & Odds ratio & $95 \%$ CI for OR & $\mathrm{p}$ value \\
\hline & \multicolumn{3}{|c|}{ Cord infection } \\
\hline \multicolumn{4}{|l|}{ CDK-use } \\
\hline No & 1.0 & & \\
\hline Yes & 0.42 & $0.18-0.97$ & 0.041 \\
\hline \multicolumn{4}{|l|}{ Area } \\
\hline Rural & 1.0 & & \\
\hline Urban & 0.15 & $0.04-0.66$ & 0.012 \\
\hline \multicolumn{4}{|c|}{ Place of delivery } \\
\hline Home & 1.0 & & \\
\hline \multirow[t]{2}{*}{ Facility } & 1.17 & $0.40-3.43$ & 0.773 \\
\hline & \multicolumn{3}{|c|}{ Puerperal infection } \\
\hline \multicolumn{4}{|l|}{ CDK-use } \\
\hline No & 1.0 & & \\
\hline Yes & 0.11 & $0.01-1.06$ & 0.057 \\
\hline \multicolumn{4}{|l|}{ Area } \\
\hline Rural & 1.0 & & \\
\hline Urban & 3.11 & $0.49-19.96$ & 0.231 \\
\hline \multicolumn{4}{|c|}{ Place of delivery } \\
\hline Home & 1.0 & & \\
\hline Facility & 5.35 & $0.83-34.34$ & 0.077 \\
\hline
\end{tabular}

no longer significant. Results of bivariate analysis showed that mothers delivering in the facility were also more likely to have a complicated delivery involving the use of forceps, ventose, and caesarean section. This study did not assess the facilities in which the women delivered. However, a study on public healthcare facilities, which included five hospitals in Upper Egypt, reported a number of substandard practices in emergency and maternity wards (27). Wards were not adequately staffed and had a shortage of basic supplies. Although conditions of delivery rooms were generally good, substandard care practices, such as breach in asepsis, and lack of monitoring of vital signs, were commonly observed. Similar shortcomings were also observed in another study of public and private hospitals in Upper Egypt (28). Despite good knowledge about infection control, actual practice was poor among physicians and nurses in maternity wards while items, such as hand-washing brushes, betadine, and gloves, were in short supply or sometimes unavailable.

Making CDKs readily available at and through government facilities, private clinics, pharmacies, or other commercial channels, along with messages targeting clean delivery practices, could help reduce rates of infection $(23,29)$. It is important to ensure that health-education messages are not only targeted to mothers but also include decision-makers within the household (30). Social marketing to ensure widespread knowledge of availability and benefits of CDKs are integral to the promotion of CDKuse (30). This study ensured that dayas visited the clinic to obtain a CDK and, in the process, received education about importance, use, and disposal of kits. This strategy could foster much-needed links between local birth attendants and primary-care facilities. A study in Pakistan successfully used a similar approach in which local TBAs were issued CDKs from the primary-care facility, enhancing channels of communication between the TBAs and the facilities (24).

The number of deliveries identified in the study area is in line with another study conducted in the same area in 1999 to assess practices of birth attendants during the antenatal, intrapartum and neonatal periods (31). Based on these data, the projected number of deliveries for the study area was 4,198 per year or 350 per month. Of these, $21 \%$, $46 \%$, and $33 \%$ of mothers were expected to deliver 
in Nena, Awana, and Inhnasia city, based on their respective populations. The results of our study correspond very closely to these figures. We identified 334 women (95\% of expected), of which approximately $22 \%, 44 \%$, and $34 \%$ were from Nena, Awana, and Ihnasia city respectively.

Since this study was based on retrospective recall of kit-use by the mother, there is a possibility of recall-bias for events surrounding delivery. However, since $90 \%$ of the neonates were aged $\leq 5$ days when the interview was conducted, this bias should be minimal.

The reduced rates of cord and puerperal infections among CDK-users in our study are consistent with the findings of other studies $(23,25,29)$. Although there are no exact estimates for the incidence of umbilical stump infection and puerperal sepsis in Egypt, our rate is close to the overall rate estimated in Nepal (5.5\%) for umbilical infection (11). Our estimate for incidence of puerperal sepsis of $1.5 \%$ also lies within the range of 1-4\% usually reported (32). However, since puerperal infection can be defined as having occurred anytime during the first 10 days postpartum (12) and since 90\% of the women in our sample were visited $\leq 5$ days postpartum, the incidence of $1.5 \%$ may underestimate cases of puerperal infection among the population.

Important intermediate outcomes of CDK-use, such as increased hand-washing, including use of soap, can also be impacted through promoting CDK-use. In Nepal, CDK-users among untrained birth attendants were more likely to wash their hands with soap before delivery compared to untrained attendants who did not use a CDK (23). Unlike our study, which did not collect data on the use of individual items in the CDK, a study from Tanzania included item-wise analysis and showed that the use of particular items in the CDK led to reductions in cord and puerperal infections (25). For example, $0.2 \%$ of mothers who delivered in the presence of an attendant who washed their hands and wore the kit-gloves developed puerperal sepsis while $1.5 \%$ of mothers who delivered in the presence of an attendant who only washed their hands and did not use kit-gloves developed puerperal sepsis. In areas where deliveries in the home assisted by TBAs are still common, the CDK can thus be an important medium through which clean delivery practices can be promoted while simultaneously working to upgrade facilities and promote institutional deliveries.

This study found that neonates born in urban areas were less likely to have an umbilical cord infection compared to neonates born in rural areas, even after adjusting for CDK-use and place of delivery. This could possibly be attributed to cord care and hygiene practices. A study conducted in the rural areas of Fayoum, Luxor and Aswan Governorates found that hand-washing among caregivers was not routine, especially after diaper changes and before feedings (33). Several products, such as alcohol (68\%) and kohl (37\%), were commonly applied to the umbilical cord-stump. The diaper was found to cover the umbilical cord-stump in $54 \%$ of cases. Colonization of neonatal skin with pathogenic bacteria, which predisposes infants to infection, may occur due to handling by unclean hands of the caregiver. Hygienic umbilical cord care can reduce bacterial colonization and infection (34). Applications of substances, such as alcohol and kohl, to the cord should be avoided, the cord should be kept clean, and the diaper should be folded away from the stump to facilitate drying. Promising but yet unproven interventions, such as chlorhexidine for cord-cleansing and body-cleansing for newborns $(5,35)$, skin barrier-enhancing emollients for newborns $(36,37)$, vitamin A for newborns (38-40), and misprostol for active management of the third stage of labour $(41,42)$, could ultimately, once demonstrated unequivocally to be efficacious, be incorporated into the CDK to enhance cost-effectiveness. In settings with limited resources and poor health systems, emphasis on family and community-based interventions can, at a relatively low cost, lead to a significant reduction in the number of deaths (43). The CDK can serve as an important component of an integrated package of services in the fight against neonatal and maternal mortality in low-resource settings around the world.

\section{ACKNOWLEDGEMENTS}

This study was supported by the United States Agency for International Development through the Healthy Mother/Healthy Child Results Package grant to John Snow, Inc., Cairo, Egypt.

\section{REFERENCES}

1. Lawn JE, Cousens S, Zupan J; Lancet Neonatal Survival Steering Team. 4 million neonatal deaths: When? Where? Why? Lancet 2005;365:891-900.

2. World Health Organization. Care of the umbilical cord: a review of the evidence. Geneva: World Health Organization, 1998. 38 p. (WHO/RHT/MSM/98.4).

3. Stoll BJ. The global impact of neonatal infection. Clin Perinatol 1997;24:1-21. 
4. Mullany LC, Darmstadt GL, KatzJ, Khatry SK, LeClerq SC, Adhikari RK et al. Development of clinical sign based algorithms for community based assessment of omphalitis. Arch Dis Child Fetal Neonatal Ed 2006;91: F99-104.

5. Mullany LC, Darmstadt GL, Khatry SK, Katz J, LeClerq SC, Shrestha S et al. Topical applications of chlorhexidine to the umbilical cord for prevention of omphalitis and neonatal mortality in southern Nepal: a community-based, cluster-randomised trial. Lancet 2006;367:910-8

6. Mullany LC, Darmstadt GL, Katz J, Khatry SK, LeClerq SC, Adhikari RK et al. Risk of mortality subsequent to umbilical cord infection among newborns of southern Nepal: cord infection and mortality. Pediatr Infect Dis J 2009;28:17-20.

7. Kwast BE. Puerperal sepsis: its contribution to maternal mortality. Midwifery1991;7:102-6.

8. Hussein J, Fortney JA. Puerperal sepsis and maternal mortality: what role can new technologies play?. Int J Gynecol Obstet 2004;85:S52-61.

9. Chisembele M. The global incidence of puerperal sepsis: protocol for a systematic review. Geneva: World Health Organization, 2004. 16 p.

10. Koblinsky M, Matthews Z, Hussein J, Mavalankar D, Mridha MK, Anwar I et al. Going to scale with professional skilled care. Lancet 2006;368:1377-86.

11. Mullany LC, Darmstadt GL, Katz J, Khatry SK, LeClerq SC, Adhikari RK et al. Risk factors for umbilical cord infection among newborns of southern Nepal. Am J Epidemiol 2007;165:203-11.

12. World Health Organization. Mother-Baby Package: implementing safe motherhood in countries. Geneva: World Health Organization, 1994. 89 p.

13. Campbell O, Gipson R, el-Mohandes A, Issa AH, Matta N, Mansour E et al. The Egypt national perinatal/neonatal mortality study 2000. J Perinatol 2004;24:284-9.

14. Darmstadt GL, Hussein MH, Winch PJ, Haws RA, Lamia M, El-Said MA et al. Neonatal home care practices in rural Egypt during the first week of life. Trop Med Intl Health 2007;12:783-97.

15. Mullany LC, Darmstadt GL, Khatry SK, Katz J, LeClerq SC, Shrestha SR et al. Topical applications of chlorhexidine to the umbilical cord prevent omphalitis and reduce neonatal mortality in southern Nepal: a community-based, cluster-randomized trial. Lancet 2006;367:910-8.

16. Mullany LC, FaillaceS, TielschJM, Stolzfus RJ, Nygaard $\mathrm{KE}$, Kavle JA et al. Incidence and risk factors for newborn umbilical cord infections on Pemba Island, Zanzibar, Tanzania. Pediatr Infect Dis J 2009;28:503-9.
17. Campbell O, Gipson R. National maternal mortality study, Egypt 2000: report of findings and conclusions. Cairo: Directorate of Maternal and Child Health Care, Ministry of Health and Population, Government of Egypt, 2001.

18. Darmstadt GL, Hussein MH, Winch PJ, Haws RA, Gipson R, Santosham M. Practices of rural Egyptian birth attendant practices during the antenatal, intrapartum, and early neonatal periods. J Health Popul Nutr 2008;26:36-45.

19. World Health Organization. Guidelines for introducing simple delivery kits at the community level. Geneva: Maternal and Child Health Unit, Division of Family Health, World Health Organization, 1987. 47 p.

20. Balsara ZP, Hussein MH, Winch PJ, Gipson R, Santosham M. Darmstadt GL. Impact of clean delivery kit use on clean delivery practices in Beni Suef governorate, Egypt. J Perinatol 2009 (in press).

21. Kapoor SK, Reddaiah VP, Lobo J. Control of tetanus neonatorum in a rural area. Indian J Pediatr 1991;58:341-4.

22. Nessa S, Arco ES, Kabir IA. Birth kits for safe motherhood in Bangladesh. World Health Forum 1992;13:66-9.

23. Tsu V. Nepal. Clean home delivery kit. Evaluation of the health impact. 2000, Seattle, Washington: Program for Appropriate Technology in Health, 2000. 36 p.

24. Jokhio AH, Winter HR, Cheng KK. An intervention involving traditional birth attendants and perinatal and maternal mortality in Pakistan. N Engl J Med 2005;352:2091-9.

25. Mosha F, Winani S, Wood S, Changalucha J, Ngasalla B. Evaluation of the effectiveness of a clean delivery kit intervention in preventing cord infection and puerperal sepsis among neonates and their mothers in rural Mwanza Region, Tanzania. Tanzan Health Res Bull 2005;7:185-8.

26. El-Zanaty F, Way A. Egypt demographic and health survey 2005. Cairo: Ministry of Health and Population, Government of Egypt, 2006. 375 p.

27. John Snow Incorporated. Neonatal and obstetrical assessment and care practices in healthcare facilities. Cairo: Healthy Mother/Healthy Child Results Package, John Snow Incorporated, 2000.

28. Winch PJ, Husein MH. Pilot testing of interventions to promote compliance with standard infection control procedures by healthcare providers. Cairo: Healthy Mother/Healthy Child Results Package, John Snow Incorporated, 2000:1-48.

29. Winani S, Wood S, Coffey P, Chirwa T, Mosha F, Changalucha J. Use of a clean delivery kit and factors associated with cord infection and puerperal sepsis in Mwanza, Tanzania. J Midwifery Womens Health 2007;52:37-43. 
30. Beun MH, Wood SK. Acceptability and use of clean delivery kit in Nepal: a qualitative study. J Health Popul Nutr 2003;21:367-73.

31. John Snow Incorporated. JSI task five milestone report, PR-6: Birth attendant practices during the antenatal, intrapartum and early neonatal periods. Cairo: Healthy Mother/Healthy Child Results Package, John Snow Incorporated, 2000.

32. Filippi VGA. Validation of women's perception of near-miss obstetric morbidity in South Benin. London: London School of Hygiene and Tropical Medicine, 1999. (PhD thesis).

33. Darmstadt GL, Hussein MH, Winch PJ, Haws RA, Lamia M, El-Said MA et al. Neonatal home care practices in rural Egypt during the first week of life. Trop Med Int Health 2007;12:783-97.

34. Garner P, Lai D, Baea M, Edwards K, Heywood P. Avoiding neonatal death: an intervention study of umbilical cord care. J Trop Pediatr 1994;40:24-8.

35. Tielsch JM, Darmstadt GL, Mullany LC, Khatry SK, Katz J, LeClerq SC. Impact of newborn skin-cleansing with chlorhexidine on neonatal mortality in southern Nepal: a community-based, cluster-randomized trial. Pediatrics 2007;119:e330-40.

36. Darmstadt GL, Badrawi N, Law PA, Ahmed S, Bashir $\mathrm{M}$, Iskander I et al. Topically applied sunflower seed oil prevents invasive bacterial infections in preterm infants in Egypt: a randomized, controlled clinical trial. Pediatr Infect Dis J 2004;23:719-25.

37. Darmstadt GL, Saha SK, Ahmed AS, Chowdhury MA, Law PA, Ahmed S et al. Effect of topical treatment with skin barrier-enhancing emollients on nosocomial infections in preterm infants in Bangladesh: a randomised controlled trial. Lancet 2005;365:1039-45.

38. Bhutta ZA, Darmstadt GL, Hasan BS, Haws RA. Community-based interventions for improving perinatal and neonatal health outcomes in developing countries: a review of the evidence. Pediatrics 2005;115(2 Suppl):519-617.

39. Tielsch, JM, Rahmathullah L, Thulasiraj RD, Katz $\mathrm{J}$, Coles $\mathrm{Cl}$. Newborn vitamin A dosing reduces the case fatality but not incidence of common childhood morbidities in South India. J Nutr 2007;137:2470-4.

40. Humphrey JH, Agoestina T, Wu L, Usman A, Nurachim $\mathrm{M}$, Subardja D. Impact of neonatal vitamin A supplementation on infant morbidity and mortality. J Pediatr 1996;128:489-96.

41. Winani S, Wood S, Coffey P, Chirwa T, Mosha F, Changalucha J. Use of a clean delivery kit and factors associated cord infection and puerperal sepsis in Mwanza, Tanzania. J Midwifery Womens Health 2007;52:37-43.

42. Parsons SM, Walley RL, Crane JM, Matthews K, Hutchens D. Oral misoprostol versus oxytocin in the management of the third stage of labour. J Obstet $G y$ necol Can 2006;28:20-6.

43. Darmstadt GL, Walker N, Lawn JE, Bhutta ZA, Haws RA, Cousens S. Saving newborn lives in Asia and Africa: cost and impact of phased scale-up of interventions within the continuum of care. Health Policy Plan 2008;23:101-17. 